\title{
EARLY EVIDENCE ON THE XBRL ADOPTION PROCESS IN MALAYSIA: DRIVERS AND CHALLENGES ON THE TECHNOLOGICAL PERSPECTIVE
}

\author{
Azleen Ilias ${ }^{1}$, Erlane K Ghani ${ }^{* *}$, Zubir Azhar ${ }^{3}$ \\ ${ }^{1}$ College of Business and Administration, Universiti Tenaga Nasional, Malaysia $2{ }^{2 *}$ Faculty of Accountancy, Universiti \\ Teknologi MARA Selangor, Malaysia; ${ }^{3}$ School of Management, Universiti Sains Malaysia, Malaysia. \\ Email: "erlanekg@uitm.edu.my
}

Article History: Received on $25^{\text {th }}$ February 2020, Revised on $18^{\text {th }}$ August 2020, Published on $29^{\text {th }}$ September 2020

\section{Abstract}

Purpose: This study aims to identify technological factors and how these factors influence the XBRL adoption process of the regulators in Malaysia.

Methodology: This paper applied Rogers's (1983) adoption process and DiPietro, Wiarda, and Fleischer's (1990) Technological, Organisational, and Environmental (TOE) framework. The paper adopted a case study approach consisting of an interview and document analysis. The data has been analysed with thematic analysis.

Results: This paper shows ten (10) factors within the technological perspective- the relative advantage as driving factor while trialability are the challenging factor in the knowledge and persuasion phase. In the decision-making phase, compatibility of XBRL taxonomy and stability production of XBRL instance documents are the driving factors whilst stability of XBRL taxonomy, standardised XBRL taxonomy, standardised XBRL submission, availability of tools and software and observability are challenges in the XBRL adoption process. In the implementation and confirmation phase, the complexity of the XBRL taxonomy is considered a challenge in the XBRL adoption process.

Implications: The findings in this paper serve as strategies to the other regulators that have plans to adopt XBRL as well as to attract the different government agencies to start with XBRL for reporting.

Keywords: Adoption Process, XBRL, Drivers, Challenges, Regulators, Malaysia.

\section{INTRODUCTION}

The earlier form of financial reporting often involved the preparation of the financial reports using various technologies from paper-based to sharing financial information through the internet in the way of digital financial reporting. In exchanging the information, the distribution of financial reporting had started with the printed financial statements and CD-ROMs, then the distribution of financial reports through the internet. However, the electronic technologies such as Portable Document Format (PDF), Microsoft Word, and Excel Spreadsheet (Lymer, Debreceny, Gray\& Rahman, 1999) are often similar to the paper-based of printed annual reports (FASB, 2000). Another technology that is commonly used is the Hypertext Markup Language (HTML) that supports navigation and links between pages. However, HTML concerns more on presentation and graphics (Lymer et al., 1999), and the web pages are viewed in browsers (FASB, 2000). Pollock and Papiernik (2001), however, argued that these digital technologies are not compatible across various computer programs. This means that the reporting technologies do not allow the system to process paper-based data into meaningful and useful information. Thus, preparers need to re-key data from paper-based financial reports into their system in order to process and manipulate data according to their needs and requirements. Often, the process of rekeying data into the system creates errors. Subsequently, digital technologies evolved into a meaningful way of reporting, which allowed data to be defined with specific meanings. This reporting technology is known as Extensible Business Reporting Language (XBRL), and it caters specifically for financial reporting. Hoffman (1999) suggested that XBRL could transform the traditional financial reporting to a higher level of financial reporting since it increases the quality of financial reporting characteristics. In addition, it transforms the formal reporting process to a more sophisticated process using computer programs that understand financial reporting data. However, since its development in 1999, this technology has yet to be fully implemented around the world, particularly in Malaysia. This can be seen due to the growth of XBRL adoption throughout the world started in the US, Australia, and the Netherlands., there are various of countries that has adopted the XBRL which is in the UK, Japan, Denmark, Europe, Russia, Belgium, France, German, India, China, and Singapore. Together with the development, some regulators have adopted the XBRL such as the Japan Financial Services Agency, US Federal Deposit Insurance Corporation, Her Majesty's Revenue, and Customs and Australian Prudential Regulatory Authority. Hence, it would be interesting to examine why such a scenario exists. XBRL adoption has spread throughout the world since it was first introduced in the US (Cohn, 2018). Three countries have successfully adopted XBRL, namely the US, Australia, and the Netherlands, in which their regulators demonstrated the benefits of data sharing among governments and regulators (Cordery et al., 2011). The jurisdiction, facilitated by XBRL International, had encouraged XBRL adoption by assisting representatives from each country to work on XBRL business reporting, XBRL taxonomy, and providing education and training on XBRL (XBRL International, 2018). As in 2018, there were 21 XBRL jurisdictions established by XBRL International. 
In Malaysia, various studies have suggested that companies lacked of the initiative to adopt XBRL given that their current practices are not aligned to online financial reporting (Homayoun, Rahman \&Bashiri, 2011; Ilias \& Ghani, 2015; Ilias, Ghani, Azhar\& Said, 2016). For example, Homayoun et al. (2011) stated that none of the public listed companies in Malaysia have disclosed or communicated information via XBRL, an indication that Malaysian companies have yet to prepare and adopt XBRL. Similar results were found by Ilias and Ghani (2015), whereby out of the 100 public listed companies, 24 had prepared their financial reporting using HTML and online interactive methods but not XBRL. The lack of preparation of XBRL among companies due to the lack of XBRL adoption among regulators. The lack of submission of using XBRL has shown that the financial report in Malaysia is not aligned with the international interest among countries on related to the usage of XBRL. As suggested by Cordery et al., (2011), the regulator is one of the key actors in the XBRL supply chain in which the regulator is the one that initiated the adoption of XBRL. The researchers have suggested that future studies need to investigate further XBRL adoption and factors influencing the XBRL adoption process among regulators.

\section{LITERATURE REVIEW}

Rogers (2003) stated that diffusion is a process that occurs over time and cannot be avoided when examining technology adoption. Several studies have employed the Diffusion of Innovation (DOI) framework, which uses the characteristics of adoption to explain the different rates of adoption by various technologies (Jeyaraj et al., 2006; Oliveira \& Martins, 2011; Mousa, 2013). The time dimension should be incorporated in identifying and explaining the diffusion of adoption in the adoption-decision process that involves the knowledge phase of adoption through to the decision making phase, whether there is adoption or rejection.

According to Rogers (2003), there are three phases in the adoption process, from the knowledge gathering phase until the confirmation to adopt an innovation phase. DePietro et al. (1990) also mentioned that the adoption process often involves awareness of the problem, deployment of the innovation as well as the adoption of commitment, implementation, and optimisation. In addition, DePietro et al. (1990) had indicated that Rogers' (1983) adoption process model is appropriate for investigating the XBRL adoption process, which is divided into three phases: gathering knowledge and persuasion, decision making as well as implementation and confirmation.

The adoption process for regulators could investigate through the three stages of the adoption process. In related to understand the adoption process, the TOE framework is necessary to investigate how factors from technological, organisational, and environmental perspective could influence the regulators to initiate, making decisions, and implement the XBRL. As to date, in the area of XBRL, only in the study by Mousa (2010) had applied the XBRL adoption-decision process that incorporates the TOE framework. Mousa (2010) had explored the factors throughout the period of gathering knowledge until the confirmation phase for e-government (XBRL).

This paper focuses on the technological perspective which refers to the description of both internal and external technologies, including current internal practices and equipment as well as the available technologies external to a company and how the technology's features can influence the adoption process (DePietro et al., 1990). DePietro et al. $\underline{(1990)}$ examined the availability of technology and contemporary technology that fits a company's current technology platform as two factors affecting the decision to adopt the technology. This perspective is in line with the factors suggested by Rogers (2003), such as relative advantage, compatibility, complexity, trialability, and observability. These factors, which are explained below, can either become drivers or challenges to the XBRL adoption process in a different scenario.

Some of the factors raised by previous researchers in related to XBRL adoption are a relative advantage (Mousa, 2010; Cordery et al., 2011; Henderson et al., 2012; Steenkamp \& Nel, 2012; David, 2016), compatibility (Cordery et al., 2011; Henderson et al., 2012; Steenkamp \& Nel, 2012), complexity (Troshani and Doolin, 2005; Troshani\& Rao, 2007; Henderson et al., 2012), trialability (Doolin\&Troshani, 2007; Cordery et al., 2011; David, 2016), observability (Doolin\&Troshani, 2007; Pinsker\& Li, 2008), stability (Troshani\& Rao, 2007; Mousa, 2010; David, 2016), cost of software (Troshani\& Rao, 2007; Dunne et al., 2013) and cost of XBRL solutions (Troshani\&Doolin, 2005).

\section{RESEARCH METHODOLOGY}

A case study approach is deemed useful for this kind of study, as suggested by Benbasat et al. (1987), when the research is at the early and formative stages. In addition, Benbasat et al. (1987) also emphasised that using a case study that examines a phenomenon in its natural setting, employing multiple methods of data collection in order to gather information from one or few entities. As in XBRL research, the researchers examined XBRL-related phenomena in its natural setting and gained an in-depth understanding of the nature and complexities of the adoption scenario (Mousa, 2010; David, 2016).

This paper focuses on multiple case studies for a period of time that was based on three different phases of the XBRL adoption process and factors that influenced the adoption process. This study has employed multiple case studies, whereby data were gathered from the key informant involved in XBRL adoption in Malaysia for four regulators with a different timeline. The four regulators consist of REGULATOR 1, REGULATOR 2, REGULATOR 3 and 
REGULATOR 4 as a case study on Malaysia which is represented in the multiple case studies for XBRL adoption in Malaysia which enabled an analysis of data across cases (Cavaye, 1996) according to the various setting.

\section{Case Description Background}

Based on the research objectives that highlighted earlier, the selected regulators are the main focus of this study as it investigates the XBRL adoption process in Malaysia. There are four regulators in Malaysia that involved in XBRL adoption, which is REGULATOR 1, REGULATOR 2, REGULATOR 3, and REGULATOR 4.

REGULATOR 1 represents financial system, REGULATOR 2 is responsible for the capital market, REGULATOR 3 regulates companies and businesses and REGULATOR 4 is accountable for collecting revenue. The selected four regulators are treated as the four cases for this study of the adoption process in Malaysia. The four regulators were selected in this current study due to their experiences in the adoption process as they play a key role to initiate the adoption of XBRL. This is because the regulators play a key role in expediting XBRL adoption, such as in the US (Abdullah, Khadaroo \& Shaikh, 2009).

\section{The Participants}

The selection of participants was based on purposive sampling because the researcher intended to select among executive from the XBRL team in order to learn and understand the central phenomena of XBRL adoption among Malaysian regulators. They have participated in the journey of developing XBRL taxonomy, platform, reporting, and the requirement for reporting which able to share the experience on the adoption process. The key person involved in XBRL adoption from each regulator was approached for the purpose of data collection. Qualitative data were collected by using interviews with 16 participants from the four regulators. Each participant was assigned a code namely, REGULATOR 1 (B1,B2,B3,B4), REGULATOR 2 (C1,C2,C3,C4), REGULATOR 3 (S1,MI4,I1,01) and REGULATOR 1 (L1,L2,M1).

\section{Data Collection}

This study employed the semi-structured interview since the researcher had close and direct contact with the interviewees. This is because this study interviewed participants who were involved directly with XBRL adoption process in Malaysia. The response from interviews were complemented by other types of sources, such as the press, media and other internal document publications. In this study, the researcher had used both external and internal documents to obtain information regarding XBRL for each regulator.

In this study, the researcher interviewed 16 participants representing the regulators that we are able to provide data pertaining to research questions. The participants who were directly involved in XBRL adoption in Malaysia played the role of the main actors or participants in this study by providing feedback for the regulators being carried out from 22 December 2014 until 4 August 2017.

\section{Data Analysis}

This study conducted data analysis, as suggested by Miles et al. (2014), which consisted of both preparation and analysis of the data. In this study, the data coding has made use of the manual process instead of using any software, such as Nvivo. The researcher read and understood each word and phrase in the transcription. From the understanding and interpretation of the researcher, the researcher has developed descriptive coding as suggested by Miles et al. (2014). Next, the second cycle coding is conducted by utilising pattern coding, which is to group the summaries into a smaller number of themes. The pattern codes are explanatory or inferential codes that identify an emergent theme (Miles et al., 2014). Hence, the second cycle coding is made based on the pre-determined coding together with undetermined factors.

\section{RESULTS AND DISCUSSION}

Due to the challenges in past practices, regulators have identified and understood that XBRL provides a relative advantage to their submission process, whether within the organisation or with their filers. In this phase, they realise that XBRL provides benefits based on each regulator's needs. Usually, the regulators are concerned about producing highquality data from the adoption of XBRL, whereby they need accurate and reliable data to be used for any decisionmaking process within the organisation. The relative advantage could drive regulators to improve past practices. Thus, relative advantage is a factor that persuades regulators to further understand XBRL implementation. Table 1 illustrates some of the selected quotation as an example to show the extent of the relative advantage that found in those cases. Hence, by understanding XBRL, REGULATOR 1 had realised the advantages offered by XBRL adoption. They believed that the data produced could consolidate reliable financial and economic statistical data and meet their expectations for data demand.

Similarly, REGULATOR 2 also realised that XBRL could provide benefits for REGULATOR 2 by producing highquality data and reduce information asymmetry. REGULATOR 3 was aware of the advantages that come along with XBRL adoption in their organisation. They agreed that XBRL benefits both regulators and filers, who produce financial and non-financial information that can be shared and exchanged easily between regulators and companies. REGULATOR 4 saw the benefits available by implementing XBRL, particularly comprehensive financial statements for tax audit operations. XBRL has been implemented by various regulators and government agencies in Asia, Europe, and 
America. At the early phase of gathering information, each regulator involved in XBRL development has to identify and understand the XBRL concept. The regulators tried to understand how XBRL benefits the preparation of reports and how it suits their current environment. They started with the initiative to learn more about XBRL with each regulator understanding the benefits of XBRL implementation. Table 1 illustrates some of the selected quotation as an example to show the extent of the relative advantage that found in those cases.

Table 1: Table of Sample for Quote for "Relative Advantage"

\begin{tabular}{ll}
\hline Officer & Quotation \\
\hline Officer O1 & $\begin{array}{l}\text { REGULATOR 3 and other regulatory bodies see the numerous needs and benefits of XBRL to the } \\
\text { country such as bringing in more foreign investors, provide deep insights into the financial health of } \\
\text { businesses, provide critical business data to the government for policy decisions and so on. }\end{array}$ \\
\hline Officer L1 & $\begin{array}{l}\text { The reason for the submission to XBRL is that XBRL is capable of producing beautiful data, so we } \\
\text { do not have to provide people for data entry, when you manually submit, have data entry, we need to } \\
\text { key in the data to get into our system, sometimes if there is a human error in the wrong key. If you } \\
\text { enter you're (company) own, then you (the company) will confirm that the data is correct. }\end{array}$ \\
\hline
\end{tabular}

At the gathering of knowledge and persuasion phase, challenges posed by past practices and relative advantage have driven regulators to adopt XBRL. This study found that regulators had the interest and initiative to adopt XBRL in order to reap its benefits. Regulators saw that XBRL could improve their current practice of preparing financial statements and collecting data from filers for the purpose of data analysis. In the UK, Mousa (2010) found that relative advantage influenced the XBRL adoption process during the knowledge gathering phase. While in the US, Henderson et al. (2012) found that relative advantage strongly influenced the internal decision to adopt XBRL. As opposed to the scene in New Zealand, there was no relative advantage in the adoption of XBRL (Cordery et al., 2011) since organisations disagreed that XBRL could reduce compliance cost. Doolin and Troshani (2007) and Steenkamp and Nel (2012) found that there was a lack of relative advantage when adopting XBRL. David (2016) suggested that the government and private organisations did not seek to adopt XBRL because the costs were perceived to exceed the benefits.

During the knowledge gathering and persuasion phase, trialability was another factor that could influence XBRL adoption. In Malaysia, REGULATOR 2 and REGULATOR 4 were keen to know how XBRL could be implemented on a trial basis even though XBRL was still new in Malaysia. This is because REGULATOR 2 had intentions to better understand how XBRL could be implemented in order to reap the benefits of XBRL. Since XBRL adoption was limited to REGULATOR 1, REGULATOR 2 wanted to know how XBRL could be accepted by filers. Meanwhile, REGULATOR 4 also wanted to know how the pilot project could ensure XBRL readiness. Both REGULATOR 2 and REGULATOR 4 had adopted XBRL on a trial basis as they had sincere intentions to understand and adopt XBRL on a trial basis before the actual adoption. During this phase, regulators gathered ideas from the small-scale trials initiated by REGULATOR 1 since REGULATOR 1 was an early adopter. REGULATOR 1 had adopted XBRL after limited trials prior to deciding. The pilot test by REGULATOR 1 could influence other regulators (REGULATOR 2, REGULATOR 3 , and REGULATOR 4) to decide whether to adopt the XBRL at the later phase. In the extent of trialability, examples of selected quotation shown in Table 2.

Table 2: Table of Sample for Quote for "Trialability"

\begin{tabular}{ll}
\hline Officer & Quotation \\
\hline Officer C1 & $\begin{array}{l}\text { I think what we are looking in the earliest days is whether the technology is ready as what people } \\
\text { create, now we heard people saying a lot of good things, it may not be so good to implement it, there } \\
\text { are XBRL stage that has some benefits, that is why we started a pilot project. We wanted to know } \\
\text { how XBRL benefits the market. }\end{array}$ \\
\hline Officer C1 & $\begin{array}{l}\text { We are looking at how we apply XBRL to the Malaysian capital market; we want to know those how } \\
\text { to benefit XBRL to the market. }\end{array}$ \\
\hline Officer C1 & $\begin{array}{l}\text { At least we try to get attraction as soon as possible. Otherwise, the technology is sitting there, every } \\
\text { year it will incur the cost before using it and become obsolete. }\end{array}$ \\
\hline
\end{tabular}

In the case of this study, the trialability could be a challenge to regulators as each regulator faces limited adoption in the Malaysian context due to limited trials on XBRL by regulators. Comparatively, most past studies (Doolin\&Troshani, 2007; Cordery et al., 2011; David, 2016) found that trialability was an important, influential factor to XBRL adoption. This is because Cordery et al. (2011) agreed that trialability could reduce the uncertainty during technology adoption. In relation to the current context among regulators in Malaysia, it is evident that the lack of trialability of XBRL among regulators could be a challenge to adopt when there is a challenge to the advantages of XBRL. This is because each regulator was intent on seeing how XBRL suits the current environment in order to achieve the objectives of XBRL adoption.

At the earlier phase of XBRL adoption, regulators believed that XBRL taxonomy development was compatible with current requirements and needs. This is because each regulator had to comply with their own requirements and needs as each had different ones. However, XBRL taxonomy was incompatible with REGULATOR 1 because they could not 
develop a taxonomy that was compatible with REGULATOR 1 and REGULATOR 2's current needs. At this phase, REGULATOR 1 had to learn XBRL taxonomy so that it was consistent with the structure of banking institutions. Their taxonomy was based on BASEL and IFRS, and they decided to have a detailed taxonomy in line with the requirements of banking institutions in Malaysia. REGULATOR 2 was following the MFRS for developing a taxonomy for their filers who came from the PRS. As both are considered early adopters, both regulators need to learn to develop the XBRL taxonomy based on their own needs and requirements. This is because both need to learn how to ensure the taxonomy suits the reporting that will be submitted by their filers. At this phase, the XBRL taxonomy should be compatible with the current requirements of REGULATOR 1 and REGULATOR 2.

Meanwhile, REGULATOR 3 also focused on MFRS, which is consistent with the IFRS taxonomy that focused on various types of businesses. In addition, REGULATOR 4, which deals primarily with tax computation, focuses on the Income Tax Act to develop its taxonomy. Regulators decided to have their own XBRL taxonomy, which was in line with their requirements and was known as an extension of the XBRL taxonomy. Each regulator has an XBRL taxonomy that is compatible with their own current requirements and based on their objective of having XBRL. The compatibility of the XBRL taxonomy acted as a driver of XBRL adoption since the taxonomy could fit regulators' requirements and needs. At the decision-making phase, regulators were concerned about the XBRL taxonomy and template development that they proposed to filers for the preparation of XBRL. One important matter when developing the XBRL taxonomy is to determine how the XBRL taxonomy can fit into the current practice. This is because each regulator has different requirements and regulations when determining the compatibility of the XBRL taxonomy. The compatibility of the XBRL taxonomy, from a Malaysian perspective, could drive the development that suits the requirements and regulations for capturing the needed data. Examples to illustrate the extent of compatibility of XBRL Taxonomy that found in those cases is outlined in Table 3. According to Mousa (2010), compatibility refers to the knowledge gathering phase when both organisations knew that XBRL would fit their electronic filing system because they had XML-based technologies in their electronic filing systems. In related to ensure compatibility of the XBRL taxonomy, there is a need for extension of taxonomy. However, Kim et al. (2019) has suggested that the extension of the XBRL taxonomy will increase discretionary accruals and reduce comparability. Different with Abhishek, et al. (2018), has suggested that the dynamic and complex environment has challenged the compatibility of XBRL taxonomy to suit with the requirements by regulators.

Table 3: Table of Sample for Quote for "Compatibility of XBRL taxonomy"

\begin{tabular}{ll}
\hline Officer & Quotation \\
\hline Officer L1 & $\begin{array}{l}\text { REGULATOR 4 has a target that needs to be followed, and it is possible that can be done as we are } \\
\text { ready to be able to do the pilot implementation but implementation it may be in the year 2017 } \\
\text { because we have to take time as well }\end{array}$ \\
\hline Officer B3 & $\begin{array}{l}\text { The current XBRL taxonomies have been developed with a large degree of customisation and } \\
\text { extension in order to meet the banking additional and specific statistical or regulatory reporting } \\
\text { requirements. }\end{array}$ \\
\hline Officer C2 & $\begin{array}{l}\text { Every industry have their own taxonomy to be developed. We will work with the Malaysian Stock } \\
\text { Exchange to make it in line. }\end{array}$ \\
\hline Officer S1 & $\begin{array}{l}\text { Malaysian Institute of Accountants has always communicated with the members of accountants, and } \\
\text { Malaysian Institute of Certified of Public Accountants had communicate with auditors. Thus they } \\
\text { will comment on the XBRL taxonomy }\end{array}$ \\
\hline
\end{tabular}

During this phase, regulators should ensure that the XBRL taxonomy remains stable when applied by both regulators and filers due to the possibility of changes in the XBRL taxonomy. The function of REGULATOR 1 is uniquely tailored for banking institutions, and it has limitations in coverage, which relates to limitations to financial data due to high tendency of change. Conversely, REGULATOR 2 also has different coverage for different scope of filers. Thus, they have a need to extend the taxonomy to accommodate different scopes. The extended taxonomy issue was raised by REGULATOR 3 to avoid the issue of insufficient items in the XBRL taxonomy at the initial stages of XBRL taxonomy development. As for REGULATOR 4, the changes are related to a change in budget, which impacts the calculation of formula due to a change in the budget announced each year. Hence, these are issues related to an unstable XBRL taxonomy, and they pose challenges to regulators who aim to ensure that XBRL taxonomy is used by regulators and filers. Table 4 illustrates some of the selected quotation as an example to show the extent of stability of XBRL taxonomy that found in the cases. According to David (2016), the perceived instability of the XBRL specification and taxonomy is a barrier for XBRL adoption. Similar to earlier XBRL adoptions in Australia, Troshani and Rao (2007) had noticed that unstable XBRL specifications were a major inhibitor to XBRL adoption. Furthermore, Doolin and Troshani (2007) suggested that a high degree of change creates uncertainty in an innovation, thus, reducing the willingness of organisations to experiment with or invest in the new technology and effectively hindering its adoption. Hence, due to factors such as a stable taxonomy and a suitable method for producing XBRL instance documents, regulators have raised the issue of standardising XBRL taxonomy and submission. 
Table 4: Table of Sample for Quote for "Stability of XBRL taxonomy"

\begin{tabular}{ll}
\hline Officer & Quotation \\
\hline Officer B3 & $\begin{array}{l}\text { Macroeconomic or microeconomic data is not suitable because there is a lot of change. Thus, the } \\
\text { XBRL will also quite a lot of change. The high tendency of change. }\end{array}$ \\
\hline Officer C2 & $\begin{array}{l}\text { The taxonomy will be different because we collect a lot more detail for Public listed companies. The } \\
\text { taxonomy will be different because you are collecting more details on licensing. We have already } \\
\text { different set of taxonomy for different data. }\end{array}$ \\
\hline Officer L2 & $\begin{array}{l}\text { Based on the capital computation, tax, or incentive computation. Let assume that on the incentive } \\
\text { computation that have the calculation and formula as well as have the requirement on the incentive. } \\
\text { The XBRL taxonomy will be the same, but the calculation formula will be changed. Another } \\
\text { example, if increasing of income tax rate, the formula will be affected. But, we are trying to minimise } \\
\text { in ensuring there are not too much of changes. }\end{array}$ \\
\hline Officer S1 & $\begin{array}{l}\text { REGULATOR 3 had released the XBRL taxonomy and will be applied by filers (businesses and } \\
\text { companies) because REGULATOR } 3 \text { will need to start somewhere. If let says, there is not enough } \\
\text { line items for the taxonomy; it can be referred to the manual in order to change the label of items. For } \\
\text { example, do not want to use Cost of Goods Sold (COSG), so the wording can change that suitable } \\
\text { and auditor must also help in any changes that related to the label of XBRL taxonomy. }\end{array}$ \\
\hline
\end{tabular}

In relation to XBRL taxonomy, REGULATOR 1 noticed that the challenge might be in efforts to ensure the standardisation of reporting data items because REGULATOR 1 intended to streamline reporting and other statistical data in the banking sector. Comparatively, other regulators had raised the issue of a common XBRL taxonomy that would be able to harmonise reporting among regulators. REGULATOR 2 and REGULATOR 4 intended to share the XBRL taxonomy by having one common XBRL taxonomy developed by REGULATOR 3. The common XBRL taxonomy would provide standardised data submitted by filers. Thus, this intention depends on regulators who have the intention to share the common taxonomy. However, there was a lack of standardisation in the XBRL taxonomy when this study was carried out. Thus, the taxonomy used still depended on their own XBRL taxonomy. The selected quotation as an example to show the extent of standardisation of XBRL Taxonomy that found in those cases as illustrated in Table 5. In relation to the production of XBRL instance documents, Troshani and Rao (2007) found a lack of standardisation in the way it was produced and consumed. Thus, this factor could be a challenge to Malaysian regulators when there is a lack of standardisation of XBRL taxonomy among regulators. Thus, there is important to concern on this matter because the standardisation of XBRL taxonomy would have reduced the levels of discretionary accruals as well as improve comparability as suggested by Kim et al. (2019). The standardisation of XBRL taxonomy is needed due view from Abhishek et al. (2018) has explained that when there is two different taxonomy which is brought to lack of standardisation of XBRL taxonomy for different regulators and would affect the capability of accountants to work with.

Table 5: Table of Sample for Quote for "Standardisation of XBRL taxonomy"

\begin{tabular}{ll}
\hline Officer & Quotation \\
\hline Officer B4 & $\begin{array}{l}\text { Actually, the gathering and standardising all reporting data items and dimensions in creating the } \\
\text { XBRL taxonomy will be the main challenges and time-consuming. }\end{array}$ \\
\hline Officer C1 & $\begin{array}{l}\text { Initially, the Malaysian Accounting Standard Board (MASB) will run the master XBRL taxonomy. I } \\
\text { think, at the later stage, we (among regulators) just had one set maybe come from the REGULATOR } \\
\text { 3, later we do our own extension. }\end{array}$ \\
\hline Officer L2 & $\begin{array}{l}\text { REGULATOR 3 has to make a survey on the XBRL taxonomy from the preparation of the financial } \\
\text { statement, and we will utilise the XBRL taxonomy. We will take and adapt the taxonomy from }\end{array}$ \\
& $\begin{array}{l}\text { REGULATOR 3. This is because our taxonomy is different with taxonomy from REGULATOR 3. } \\
\text { We have built a framework, so the taxonomy from REGULATOR 3 can be sued in our taxonomy. } \\
\text { Then, the standardisation can be done }\end{array}$ \\
\hline Officer S1 & $\begin{array}{l}\text { REGULATOR 3 will share the link of XBRL taxonomy for XBRL with any regulators that have } \\
\text { interest on that. As at now, the REGULATOR 4 have shown their curiosity with our XBRL } \\
\text { taxonomy; this is because REGULATOR 4 will ease the tax agent. }\end{array}$
\end{tabular}

Another factor is the stable production of XBRL instance documents for intra and inter-organisational purposes. In this phase, each regulator had considered and identified a method for producing XBRL instance documents that would attract filers to use the Excel template. REGULATOR 1 wanted to use the Excel template in order to absorb the cost of preparing XBRL. REGULATOR 2 had decided to apply a simple XBRL preparation method to avoid complicating the market and providing a more transparent process for XBRL preparation. Similarly, REGULATOR 3 had considered several methods for preparing XBRL and decided to choose a template for filers to prepare XBRL. REGULATOR 3's decision was similar to that of REGULATOR 4 since REGULATOR 4 also chose to have the Excel template to cope with a simplified tax return form that suits companies of various sizes. REGULATOR 1 required filers to prepare XBRL submissions by using the Excel format. At this phase, REGULATOR 1 must ensure the existence of adequate readiness for solving XBRL submission issues. Stability of the Excel template was similar with that of REGULATOR 2. 
Furthermore, both regulators had incorporated the validation element, whereby data submitted to filers are accurate. Meanwhile, REGULATOR 3 had carefully considered tools and the submission platform to ensure the stability of XBRL instance documents when they prepared the XBRL template, which was introduced in 2018. Whereas REGULATOR 4 had developed the computation worksheet by using the XBRL submission system. However, REGULATOR 4 took a longer time to test the system in order to ensure that the system met the necessary requirements and system architecture. The system testing was challenging to REGULATOR 4 as it had to ensure that the system was at par with expectations.

During this phase, this factor had driven regulators to adopt XBRL because regulators were more cautious in implementing an Excel-based template to attract filers to prepare XBRL. The following quotes are shown in Table 6 how the extent of stability of XBRL Instance Documents that found in those cases. This was in line with the opinion that the system was easy to use and user-friendly since the method was developed by regulators. This issue is related to the findings of Troshani and Doolin (2005) and Troshani and Rao (2007), which found that unstable XBRL specifications could pose a challenge to XBRL adoption. This is because the stability of XBRL specification on office applications and accounting packages with the integration of XBRL-enabled extensions could produce XBRL instance documents (Troshani\&Doolin, 2005). In reference to XBRL adoption in Australia, Troshani and Rao (2007) found that a lack of stability in XBRL specifications was a major inhibitor of XBRL adoption regarding how XBRL technology works. Furthermore, unstable XBRL specifications at the earlier part of XBRL adoption would continue to exist until the specifications meet current required specifications.

Table 6: Table of Sample for Quote for "Stability of XBRL Instance Documents"

\begin{tabular}{ll}
\hline Officer & Quotation \\
\hline Officer B1 & Based on the excel template, this kind of method will help to absorb the cost to prepare the XBRL. \\
\hline Officer L1 & $\begin{array}{l}\text { Will use template, is like e-filing. We are in a middle of developing the template, once done, they } \\
\text { (filers) will fill in since they (filers) does not have the template of XBRL. }\end{array}$ \\
\hline Officer C2 & $\begin{array}{l}\text { We do not want to complicate the market in term of asking them (filers) to learn about XBRL. What } \\
\text { we do is, we do something transparent for them (filers), and we created the same template, such as } \\
\text { normal filing. }\end{array}$ \\
\hline Officer S1 & $\begin{array}{l}\text { REGULATOR 3 will use the template for the filers. All this while, the filers only use pdf and papers, } \\
\text { so when XBRL is related to the technology, there is a little bit late because there is a need to change } \\
\text { the mindset of filers. }\end{array}$ \\
\hline
\end{tabular}

Regulators need to produce good-quality XBRL taxonomy as well as a stable method for producing XBRL instance documents. Only then will the stabile production of XBRL instance documents be considered in the adoption process. This because regulators need to ensure that both the XBRL taxonomy and the proposed method is stable. Regulators in this study had to ensure an easy-to-use template that would attract filers to readily prepare XBRL. Since the regulators were at the implementation phase, an appropriate template would attract filers at the early stage of implementation. Thus, stable XBRL instance documents would act as drivers during the adoption process.

In relation to XBRL submission, this study can be interpreted that there are issues related to the standardisation of XBRL submission by filers. REGULATOR 1 filers are slightly different compared to REGULATOR 2, REGULATOR 3 and REGULATOR 4 in terms of producing quality data from each regulator. During this phase, the consideration of standardising submission was related to having a single submission for filers so that they would submit only at one single platform. However, there is still a lack of standardisation in submissions due to the lack of standardisation in the XBRL taxonomy. Thus, this would be a challenge to regulators since regulators have different XBRL taxonomy and submission platforms that should be integrated in order to produce high-quality data. The lack of standardisation reduces the advantage of offering XBRL taxonomy to filers since they need to submit XBRL to different regulators. An example of the extent of standardisation of XBRL submission that found in those cases is illustrated in table 7. Mousa (2010) also commented on the issue of having joint-filing between regulators. However, one of the regulators had started to face privacy and security challenges with the implementation of XBRL-based joint-filing facility with another regulator. While, Liu et al. (2019) suggested that standardisation platform system is for the purpose to ensure efficiently and conveniently to integrate various types of data. Recently in the UK scenario, Alkhatib, et al. (2019) has found that there are challenges in the implementation of joint filing facility when there are different submission and limited awareness among small companies.

Table 7: Table of Sample for Quote for "Standardisation of XBRL submission"

\begin{tabular}{ll}
\hline Officer & Quotation \\
\hline Officer B1 & The integration of data is important and must be parallel run on the XBRL. \\
\hline Officer C3 & $\begin{array}{l}\text { Filers will submit only one file which follows the XBRL which we consolidate few things in that } \\
\text { system; then when we received, we disseminate according to whatever department's needs, so it is } \\
\text { means we do not burden the filers. }\end{array}$ \\
\hline Officer L1 & $\begin{array}{l}\text { For companies (filers), the submission is not through our platform; the submission needs to submit } \\
\text { through REGULATOR 3. But, the REGULATOR 3 is not yet ready. So, we need to start to do. }\end{array}$ \\
\hline Officer S1 & REGULATOR 3 can share with regulator that have interest as we can see that REGULATOR 4 is \\
\hline
\end{tabular}




\section{Officer Quotation}

interested. We always communicate and discuss with REGULATOR 4 because they (REGULATOR 4) can see that with this method that can make the task of tax agent will be easier.

The standardisation of XBRL taxonomy and submission was also raised in this study. This is important as it would ensure that data produced is in line with needs and requirements. Furthermore, this study showed that REGULATOR 2, REGULATOR 3 and REGULATOR 4 were interested in a common XBRL taxonomy and single submission, which might be advantageous to both regulators and filers. REGULATOR 1 was concerned about standardisation when reporting data items to ensure that data from the XBRL was based on needs and requirements. At this phase, there was a lack of standardisation in the taxonomy and submission method, which could impact as challenges to the adoption process as there was no decision to ensure the standardisation.

There were three regulators who were concerned about the availability of tools and software regarding the readiness to adopt XBRL. Each regulator had instructed filers to prepare XBRL and the template. Furthermore, filers had the option of several methods that they could choose in order to prepare the XBRL. The implementation of XBRL enables a degree of automation, which adds to the company's costs. The banking sector has the financial power as it comprises bigger companies compared to other public limited companies, when adopting computerised and automated operations. XBRL can be produced by using accounting software since REGULATOR 3 was concerned on how accounting software can be used by filers. In addition, Abhishek et al. (2018) has suggested that the computerised and automation of XBRL is needed in order to ensure the implementation of XBRL.

The accounting software used by filers should be incorporated in the XBRL taxonomy and the mechanism developed by REGULATOR 3. Similarly, REGULATOR 4 also raised the issue of whether filers should use automation or accounting software incorporated in the XBRL taxonomy. REGULATOR 4 used the example of HMRC UK, which had a list of companies that provided accounting software in the XBRL mechanism. However, REGULATOR 4 was also concerned about the capability of big and small companies, whereby small companies lack the capability to adopt accounting software. That is the reason why REGULATOR 4 provided alternatives to filers to use any accounting software-based REGULATOR 4's suggestion. The availability of tools and software to filers is not a challenge to regulators since most regulators had prepared the template for XBRL preparation and submission. This could be a challenge, as in the case of Australia, whereby due to limited software tools and support, vendors were not keen to develop XBRL as there was no market demand (Troshani\& Rao, 2007). Meanwhile, Troshani and Doolin (2005) also saw limited support of XBRL software and tools for potential adopters, in which the tools needed to be standardized in the way XBRL instance documents are produced and consumed.

Furthermore, there is a need to ensure the necessary tools and software used for XBRL implementation so that XBRL can be used by filers to present the XBRL taxonomy and submission platform. In relation to this, REGULATOR 2 ensured that the system was available in the market for filers to use. REGULATOR 2 believed that the readiness of filers depended on the convenience of the filing system prepared by regulators. Similarly, REGULATOR 3 took a long time to ensure that the system and software were ready for filers to prepare XBRL. REGULATOR 4 also needed time to ensure that the XBRL system was available in the market for filers. Thus, this factor was a challenge for regulators if they had to ensure that the tools and software were available in the market. Hence, regulators are responsible for ensuring that tools and software that facilitate XBRL adoption are available. Table 8demonstrates some of the selected quotation as an example to show the extent of availability of tools and software that found in those cases. However, this would be a challenge for XBRL adoption if there is a lack of tools and software in the market (Troshani \& Doolin, 2005; Troshani \& Rao, 2007; David, 2016). Not surprisingly happened in Australia when Perdana et al. (2018) when there is a lack of companies that provide accounting software that embedded with XBRL taxonomy for filers particularly for small companies.

Table 8: Table of Sample for Quote for "Availability of tools and software"

\begin{tabular}{ll}
\hline Officer & Quotation \\
\hline Officer S1 & As we do not have any information which IT company software package that have really have the \\
& XBRL. I (REGULATOR 3) have noticed few companies that have accounting software with XBRL \\
& in Malaysia, compare with Singapore, majority Singapore companies that have accounting software \\
& with XBRL with the back-end of accounting software have solution that have used XBRL GL. There \\
& is also an IT company that incorporated in Country A that have accounting software, that is \\
& Malaysian companies that have developed accounting software with XBRL. \\
\hline Officer L1 & But in Malaysia, we have problems for small and medium-sized companies. This is because these \\
& small and medium-sized companies have problems that they do not know and can not afford to make \\
& their own financial statements. In fact, they do not even know how to store documents regularly, \\
& scattered receipts, and do not pass tax-related documents. As such, we build templates available for \\
& these small and medium-sized companies. Often like companies such as taxis, small shops, they do \\
& not have a standard template for their financial information.
\end{tabular}


In relation to the stability of the method for producing the XBRL instance documents, it is necessary to relate the availability of tools and software. Currently, regulators in Malaysia have decided to ensure an easier method for filers to prepare XBRL. However, there is also a need to ensure that there are other methods for producing XBRL that is related to the software incorporated in the XBRL taxonomy. This is because filers might be concerned about the software they use and how XBRL impacts their current practice. However, the issue of tools and software was raised by REGULATOR 2, REGULATOR 3, and REGULATOR 4 because financial institutions have a greater capability of possessing these tools and software. In addition, regulators also need to ensure that the software is user friendly so that XBRL is readily accepted. Since Malaysia is still new in the field of XBRL development, there is a lack of tools and software for filers, which could pose a challenge for XBRL adoption. With this lack of tools and software, there is a need to regulator to ensure the availability of appropriate tools and software in the market to facilitate the adoption of XBRL (Perdana et al., 2018).

During the decision-making process, observability was a factor that determined how XBRL was visible to regulators in Malaysia. This is because the XBRL provided benefits and suited the current environment of each regulator. REGULATOR 2 presumed that XBRL was ready, but the issue was to have XBRL ready for the market. In a similar vein, REGULATOR 3 suggested the XBRL would need time to be prepared for the Malaysian scene. In relation to this study, this indicates a lack of XBRL that can be observed by other regulators prior to making any decision. This is when the regulator needs to ensure that XBRL can instigate the decision to adopt based on the observation of how XBRL benefits regulators. An example of quotation on the extent of observability that found in those cases as illustrated in Table 9. In a similar vein, Doolin and Troshani (2007) said that when there is a lack of adoption, it will restrict the extent to which the benefits of XBRL are observed.

Table 9: Table of Sample for Quote for "Observability"

\begin{tabular}{ll}
\hline Officer & Quotation \\
\hline Officer C1 & $\begin{array}{l}\text { I think the most things is whether the technology is ready. A lot of times people will say a good } \\
\text { thing, we are at the stage we are looking that XBRL are having that benefits. } \\
\text { Officer S1 } \\
\text { XBRL may sometimes take in order to ensure the software and system can be ready; it will take quite } \\
\text { some times to be ready. }\end{array}$ \\
\hline
\end{tabular}

The issue of complexity in XBRL taxonomy was raised by regulators. The complexity of taxonomy is related to several elements, such as changes in taxonomy, underestimating business complexities and lack of understanding of business requirements, data complexity, data mining and complexity of submission forms. During this phase, REGULATOR 1 was concerned about business complexities and requirements as well as difficulties of data mining, while REGULATOR 2 was concerned about the review of XBRL taxonomy due to changes in requirements. However, REGULATOR 3 was concerned about the presentation layout of the XBRL taxonomy, while REGULATOR 4 had a different view about complexity, which was related to the number of tax return forms. However, REGULATOR 3 saw the complexity of XBRL, although filers disagreed. Furthermore, these complexities could be reduced by improving skilled internal resources in the organisation. From the regulator's perspective, complexity is seen as a challenge that influences the XBRL adoption process. According to Mousa (2010), technological complexity is a common factor since the challenge posed by information technology is found throughout the XBRL adoption process. In the UK scenario, Alkhatib et al. (2019) has suggested that the complexity of the tagging of the XBRL taxonomy has not influenced the decision to adopt the XBRL.

Furthermore, the complexity of XBRL taxonomy could exist, whereby REGULATOR 1 and REGULATOR 2 agreed to the factors that impacted the complexity of the XBRL taxonomy. REGULATOR 1 had foreseen that the cost of software impacted the complexity of XBRL taxonomy and data. The complexity of XBRL taxonomy is a challenge when realising the implementation of XBRL. REGULATOR 2 presumed that the complexity of XBRL taxonomy depended on the changes in the XBRL taxonomy that was experienced during XBRL implementation. This usually occurs when there is an introduction of new products as well as changes in the product, business requirements, and accounting standards. This would have an impact on the preparation and implementation of XBRL as filers need to make amendments on the XBRL taxonomy due to these changes. It would also impact the cost, especially that incurred when making changes to the taxonomy. Thus, this factor is also a challenge to regulators when stabilising the production of the XBRL instance documents. Table 10illustrates some of the selected quotation as an example to show the extent of complexity of XBRL taxonomy that found in those cases.

Table 10: Table of Sample for Quote for "Complexity of XBRL taxonomy"

\begin{tabular}{ll}
\hline Officer & Quotation \\
\hline Officer B1 & $\begin{array}{l}\text { During previous development of XBRL taxonomy, the important matter that has been forgotten is } \\
\text { underestimating the business complexities and lack of understanding for business requirements. }\end{array}$ \\
\hline Officer C3 & $\begin{array}{l}\text { The way new product can affect the changes of XBRL taxonomy, whenever there is a new product in } \\
\text { the market it will go back into the XBRL taxonomy because the taxonomy needs to be reviewed. For } \\
\text { example; previously, this product can be offered to a certain percentage of intermediaries (such as } \\
\text { stockbrokers) and then after checking, the product can be provided in a different way, maybe because }\end{array}$ \\
\hline
\end{tabular}




\begin{tabular}{ll}
\hline Officer & Quotation \\
\hline & $\begin{array}{l}\text { of there is another extension to the product, so the format and the XBRL taxonomy layout also need } \\
\text { to be reviewed. }\end{array}$ \\
\hline Officer S1 & $\begin{array}{l}\text { The complexity of XBRL taxonomy from the respective REGULATOR 1 have raised some difficulty } \\
\text { in doing the data mining. This is because by comparing the layout of REGULATOR } 3 \text { and } \\
\text { REGULATOR 1, the presentation layout of XBRL taxonomy by REGULATOR } 3 \text { can be considered } \\
\text { not too many as what has been done by REGULATOR 1. }\end{array}$ \\
\hline Officer L1 & $\begin{array}{l}\text { Related to the complexity of the XBRL taxonomy, every year, there is an issue of tax changes, and } \\
\text { the changes may continuously be updated. Thus the XBRL taxonomy must be updated, which is } \\
\text { related to tax changes. }\end{array}$ \\
\hline
\end{tabular}

According to Mousa (2010), technological complexity associated with building the XBRL taxonomy structure is a common factor and an information technology challenge in the XBRL adoption process. Cordery et al. (2011) suggested that in New Zealand, complexity in developing a structured language (taxonomy) for XBRL was a challenge. A recent study by David (2016) in New Zealand found that the element of complexity in XBRL had influenced the government and private organisations against adopting XBRL for business reporting. At the earlier stage of XBRL adoption, complexity was seen as a factor that inhibited organisations from adopting XBRL (Troshani\& Rao, 2007). Meanwhile, Doolin and Troshani (2007) found that the element of complexity could complicate the decision-maker when developing XBRL taxonomy due to specialised tasks involved in developing specific taxonomies and 'tagging' financial data.

Together with the compatibility of XBRL taxonomy, regulators need to ensure that the XBRL taxonomy would be stable when used by each regulator to cater for the scope of data as well as changes to requirements and regulations. This is because there is a possibility that changes made by regulators would impact the XBRL taxonomy, which then leads to the issue of complexity of the XBRL taxonomy. These complexities related to business requirements, data, and business would arise whenever regulators decide to fit the XBRL taxonomy with current requirements and regulations. In this case, both the stability and complexity of the XBRL taxonomy are challenges when adopting XBRL.

As indicated from the explanation of the discussion on the XBRL adoption as above, Table 11 has shown that regulators in Malaysia have seen to be ready with the XBRL when regulators have driven with the relative advantage to adopt XBRL, however they are seen to be lack limited of trial XBRL in Malaysia in order to make further decision to adopt XBRL. In the decision-making stage, the compatibility of XBRL taxonomy and the stability of the XBRL instance document (XBRL report) by regulators in Malaysia can be seen as drivers to regulators in Malaysia. This is due to the taxonomy, and the way to produce the XBRL instance document developed by regulators has made the adoption process could ensure the encouragement of XBRL adoption. Besides that, the limitation of XBRL that can be observed by regulators also challenge them to make a decision. In addition, regulators have a need to ensure the stability of XBRL taxonomy, standardisation of XBRL taxonomy, and standardisation of XBRL Submission. In this stage, regulators also saw careful to ensure the tools and software available in the market in order to ensure the readiness of XBRL among filers. For the implementation stage, the capability to manage the complexity of XBRL taxonomy would be a challenge to regulators when they need to identify a suitable way to ensure they could deal with the changes of XBRL taxonomy.

Table 11: Drivers and Challenges of Technological Factors during the Adoption Process

\begin{tabular}{|c|c|c|}
\hline \multicolumn{3}{|c|}{ Technological } \\
\hline Factors & Drivers & Challenges \\
\hline $\begin{array}{l}\text { Gathering Knowledge and } \\
\text { persuasion } \\
(\mathrm{S} 1-\text { Stage } 1)\end{array}$ & $\begin{array}{ll} & \text { Relative } \\
\text { advantage }\end{array}$ & - $\quad$ Trialability \\
\hline $\begin{array}{l}\text { Decision making } \\
\text { (S2 - Stage 2) }\end{array}$ & $\begin{array}{l}\text { - Compatibility of } \\
\text { XBRL Taxonomy } \\
\text { - Producing Stable } \\
\text { XBRL Instance } \\
\text { Documents }\end{array}$ & 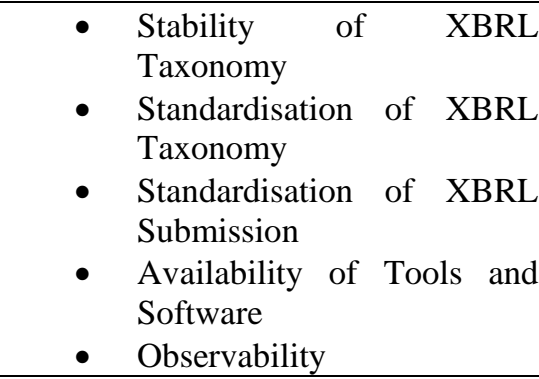 \\
\hline $\begin{array}{l}\text { Implementation } \\
\text { confirmation } \\
\text { (S3 - Stage 3) }\end{array}$ & & $\begin{array}{l}\text { Complexity of XBRL } \\
\text { Taxonomy }\end{array}$ \\
\hline
\end{tabular}

\section{CONCLUSION}

The technology perspective is discussed in this paper with the aim of identifying and understanding factors related to the decision to adopt and implement XBRL. The findings were based on several elements related to the XBRL taxonomy, 
namely relative advantage and trialability at the knowledge and persuasion level. When deciding on the XBRL taxonomy, regulators need to understand the factors associated with some aspects of XBRL taxonomy such as the compatibility, stability, and standardisation. At this phase, regulators need to understand and decide on the process that produces a stable XBRL instance document and standardises XBRL adoption. Additionally, factors related to the readiness to adopt XBRL are related to the stability required for producing XBRL instance documents and standardisation of XBRL submission. Furthermore, factors related to the availability of tools and software for regulators were discussed in the section on decision making. The complexity of the XBRL taxonomy should be well understood during the implementation and confirmation of XBRL. Understanding of the technology perspective suggests different versions of the adoption process that regulators have gone through, which is related to the development of the XBRL taxonomy and submission platform.

This study is not without limitations. This current study was limited to pre-enforcement when regulators have gone through the adoption process. Thus, the current study did not capture the stakeholder's acceptance of XBRL. Hence, the participants were not able to understand the impact of XBRL adoption by REGULATOR 1 and REGULATOR 2 for each implementation phase. Future studies should be carried out in post-implementation to identify how XBRL impacts regulators and filers as well as practitioners involved in the use of XBRL data. This shows how relative advantage can be experienced.

\section{REFERENCES}

1. Abdullah, A., Khadaroo, I., \& Shaikh, J. (2009). Institutionalisation of XBRL in the USA and UK. International Journal of Managerial and Financial Accounting, 1(3), 292. https://doi.org/10.1504/IJMFA.2009.025057

2. Abhishek, Dr., Ashoka, M. D. L. \& Divyashree, M. S., M. L. (2018). A Conceptual Study on XBRL Implementation in India: Issues and Challenges.Open Journal of Economics and Commerce, 1(4), 45-51. https://doi.org/10.9734/AJEBA/2018/45843

3. Alkhatib, E., Ojala, H., \& Collis, J. (2019). Determinants of the voluntary adoption of digital reporting by small private companies to Companies House: Evidence from the UK.International Journal of Accounting Information Systems, 1-62. https://doi.org/10.1016/j.accinf.2019.06.004

4. Benbasat, I., Goldstein, D. K., \& Mead, M. (1987). The Case Research Strategy in Studies of Information Systems. MIS Quarterly, 11(3), 369. https://doi.org/10.2307/248684

5. Cavaye, A. L. (1996). Case study research: a multi-faceted research approach for IS. Information systems journal, 6(3), 227-242. https://doi.org/10.1111/j.1365-2575.1996.tb00015.x

6. Cohn, M. (2018, June 28). SEC approves Inline XBRL for tagged financial data. Retrieved from https://www.accountingtoday.com/news/sec-approves-inline-xbrl-for-tagged-financial-data

7. Cordery, C. J., Fowler, C. J., \& Mustafa, K. (2011). A solution was looking for a problem: factors associated with the non-adoption of XBRL. Pacific Accounting Review, 2(1), 69-88. https://doi.org/10.1108/01140581111130634

8. David, J. (2016). The non-adoption of XBRL by professional and government organisations in New Zealand and its implications for stakeholders. (PhD), Victoria University of Wellington. Retrieved from: http://researcharchive.vuw.ac.nz/xmlui/handle/10063/5459

9. Depietro, R., Wiarda, E., \& Fleischer, M. (1990). The Context for Change: Organization, Technology and Environment. (, 1990). The processes of technological innovation, Lexington, Mass.: Lexington Books, 151175.

10. Doolin, B., \& Troshani, I. (2007). Organizational Adoption of XBRL. Electronic Markets, 17(3), 199-209. https://doi.org/10.1080/10196780701503195

11. Dunne, T., Helliar, C., Lymer, A., \& Mousa, R. (2013). Stakeholder engagement in internet financial reporting: The diffusion of XBRL in the UK. The British Accounting Review, 45, 167-182. https://doi.org/10.1016/j.bar.2013.06.012

12. FASB (2000), Steering Committee Report Series, 2000. Business Reporting Research Project $(B R R P)$.Electronic Distribution of Business Reporting Information. Financial Accounting Standards Board. Retrieved from http://www.fasb.org/cs/ContentServer?c=Document_C\&pagename=FASB\%2FDocument C\%2FDocumentPage \&cid=1175801856611

13. Henderson, D., Sheetz, S. D., \& Trinkle, B. S. (2012). The determinants of inter-organizational and internal inhouse adoption of XBRL: A structural equation model. International Journal of Accounting Information Systems, 13, 109-140. https://doi.org/10.1016/j.accinf.2012.02.001

14. Hoffman, C. (1999): The XML Files, Journal of Accountancy 187 (5), 71-77.

15. Homayoun, S., Rahman, R. A., \& Bashiri, N. (2011). Internet corporate reporting among public listed companies in Malaysia: An exploratory study. African Journal of Business Management, 5(30), 11863-11873. https://doi.org/10.5897/AJBM10.1406

16. Ilias, A., \& Ghani, E. K. (2015). Examining the adoption of extensible business reporting language among public listed companies in Malaysia. Procedia Economics and Finance, 28, 32-38. https://doi.org/10.1016/S2212-5671(15)01078-3 
17. Ilias, A., Ghani, E. K., Azhar, Z. \& Said, J. (2016). Governance Issues On Non-Adoption Of Xbrl In Malaysia. International Conference On Accounting Research And Education (Icare 2016) (1-9). ISSN :978-967-5741-456.

18. Jeyaraj, A., Rottman, J. W., \& Lacity, M. C. (2006). A review of the predictors, linkages, and biases in IT innovation adoption research. Journal of Information Technology, 21, 1-23. https://doi.org/10.1057/palgrave.jit.2000056

19. Kim, J. B., Kim, J. W., \& Lim, J. H. (2019). Does XBRL Adoption Constrain Earnings Management? Early Evidence from Mandated US Filers. Contemporary Accounting Research, 1-40. https://doi.org/10.1111/1911$\underline{3846.12493}$

20. Liu, D., Jun Tang, X. U. Yanlong, \& Bang, J. U. (2019). XBRL-based global data standardization platform system and construction method thereof. U.S. Patent Application 16/320,692, filed May 30, 2019.

21. Lymer, A., Debreceny, R., Gray, G. L., \& Rahman, A. (1999). Business Reporting on the Internet. A Report for the International Accounting Standard Committee. ISBN 0905625773.

22. Miles, M. B., Huberman, A. M., \& Saldana, J. (2014). Qualitative data analysis. Sage Publication.

23. Mousa, R. (2010). E-Government Adoption Process: XBRL Adoption in HM Revenue and Customs and Companies House. (PhD), University of Birmingham. Retrieved from: https://etheses.bham.ac.uk/id/eprint/1752/

24. Mousa, R. (2013). E-Government Adoption in the U.K.: XBRL Project. International Journal of Electronic Government Research, 9(2), 101-119. https://doi.org/10.4018/jegr.2013040106

25. Oliveira, T., \& Martins, M. F. (2011). Literature Review of Information Technology Adoption Models at Firm Level. The Electronic Journal Information Systems Evaluation, 14(1), 110-121.

26. Perdana, A., Robb, A., Rohde, F., \& Birt, J. (2018). Standard Business Reporting (SBR) Adoption in Australia, Critically Acclaimed, Box Office Flop: Constructivist and Ecological Rationalities in Information Systems (IS) Adoption. Australasian Journal of Information Systems, 22. https://doi.org/10.3127/ajis.v22i0.1680

27. Pinsker, R., \& Li, S. (2008). Costs and Benefits of XBRL Adoption: Early Evidence. Communication of the ACM, 51(3), 47-50. https://doi.org/10.1145/1325555.1325565

28. Pollock, K. S., \& Papiernik, J. C. (2001). XBRL: A New Common Language for Business Information Reporting. The Ohio CPA Journal, 60(1), 38-41.

29. Rogers, E. M. (1983). Diffusion of Innovations ( $3^{\text {rd }}$ ed.). New York: Free Press.

30. Rogers, E. M. (2003). Diffusion of Innovations ( $5^{\text {th }}$ ed.). New York: Free Press.

31. Steenkamp, L., \& Nel, G. (2012). The Adoption of XBRL in South Africa: an empirical study. The Electronic Library, 30(3), 409-425. https://doi.org/10.1108/02640471211241672

32. Troshani, I., \& Doolin, B. (2007). Innovation diffusion: a stakeholder and social network view. Europian Journal of Innovation Management, 10(2), 176-200. https://doi.org/10.1108/14601060710745242

33. Troshani, I., \& Rao, S. (2007). Drivers and Inhibitors to XBRL Adoption: A Qualitative Approach to Build a Theory in Under-Researched Areas. International Journal of E-Business Research, 3(4), 98-111. https://doi.org/10.4018/jebr.2007100106

34. Troshani, I., \& Doolin, B. (2005). Drivers and Inhibitors Impacting Technology Adoption: A qualitative investigation into the Australian Experience with XBRL. Proceedings of 18th Bled eConference integration in Action, (1-16). Bled, Slovenia.

35. XBRL International (2018). An Introduction to XBRL. Retrieved from: https://www.xbrl.org/ 